\title{
Avaliação como aprendizagem em ambiente on-line
}

\author{
Ana Balula \\ Universidade de Aveiro
}

\section{Resumo}

Neste trabalho, discute-se o conceito da 'avaliação das aprendizagens' numa perspetiva de 'avaliação para a aprendizagem' e de 'avaliação como aprendizagem' em ambiente on-line. Tendo isto em conta, apresentam-se alguns pressupostos que deverão estar subjacentes à avaliação das aprendizagens em ambiente on-line, nomeadamente ao nível do que se entende por objeto de avaliação e respectivo domínio da aprendizagem e da sua operacionalização. Releva-se ainda a importância que o desenvolvimento das tecnologias da informação e comunicação (TICs) poderá ter na criação de contextos de aprendizagem le de avaliação das aprendizagens) inovadores e autênticos.

Palavras-chave: Avaliação das aprendizagens on-line. Elearning. Blearning. EaD. TIC. 


\section{Assessment as learning in online environment}

In this work, the concept of assessment of learning is discussed, from the point of view of 'assessment for learning' and assessment as learning', in an online environment. Bearing this in mind, some further assumptions that should underpin e-assessment of learning are put forward, particularly as to what is understood as the object of evaluation, the respective learning domain, and its operationalization. The importance ICT development may have in the creation of innovative and authentic learning (and assessment) contexts is also underlined.

Keywords: E-assessment. E-learning. Blearning. Distance education. ICT.

\section{Evaluación como aprendizaje en el entorno on-line}

En este trabajo, se analiza el concepto de "evaluación del aprendizaje" en uma perspectiva de "evaluación para el aprendizaje" y "evaluación como aprendizaje" en el entorno on-line. Con esto en mente, presentamos algunos conceptos adicionales que deben sustentar la evaluación del aprendizaje on-line, sobre todo en términos de lo que se entiende por objeto de evaluación en el dominio del aprendizaje y su puesta en funcionamiento. Se destaca también la importancia que las TIC pueden tener en el desarrollo de la creación de ambientes de aprendizaje (y evaluación) innovadores y auténticos.

Palabras-clave: Evaluación del aprendizaje on-line. Elearning. Blearning. EaD. TIC 


\section{Introdução}

Nos dias de hoje, o processo de ensino e de aprendizagem tende a não se confinar ao espaço geográfico da sala de aula devido ao crescente desenvolvimento das tecnologias de informação e comunicação (TICs). Cada vez mais se opta por soluções que fazem convergir ambientes presenciais locais e ambientes on-line de dimensão mundial. As dinâmicas que daqui emergem vêm, então, flexibilizar os próprios contextos e processos educativos, na medida em que permitem o acesso a uma maior quantidade de informação e a cooperação e colaboração na construção de novo conhecimento. Assim, o desenvolvimento de novo conhecimento passa a ser entendido como parte de processos ativos e abrangentes, que não dependem apenas das estruturas cognitivas ${ }^{1}$ prévias de um único indivíduo e que resultam também em saberes partilhados por outros indivíduos e/ou comunidades.

Desta forma, a avaliação das aprendizagens entende-se como um processo eminentemente social e formativo orientado para os objetivos pedagógicos e competências a atingir pelos alunos; no entanto, esta deverá ser suficientemente flexível e diversificada para ir ao encontro das necessidades e características do público-alvo de acordo com o ambiente em que o processo de ensino e de aprendizagem ocorre (Balula, 2005). Em contexto on-line, é comum que se transponham estratégias do ensino presencial sem se terem em conta as características do novo ambiente, ou seja, negligenciando o facto de o sucesso da sua aplicação depender, em grande parte, da adequação que se faz ao meio e às características dos próprios participantes. Esta será uma das razões pelas quais se relega a avaliação das aprendizagens para contextos presenciais. Outra razão será o facto de haver dificuldade em se garantir a fiabilidade dos produtos apresentados pelos alunos, o que leva algumas instituições a não optarem pela avaliação das aprendizagens em ambiente on-line.

0 processo de avaliação das aprendizagens é fundamental para a evolução do indivíduo e da comunidade que ele integra, pelo que se deverão equacionar alguns dos aspectos que a caracterizam, condicionam, auxiliam e dificultam quando realizada em ambiente on-line. Este trabalho procurará colocar em evidência questões várias que o ambiente on-line levanta não só em relação ao conceito, mas também ao que se entende por objeto da própria avaliação e aos pressupostos de operacionalização dos instrumentos que podem ser utilizados para ensinar, aprender e avaliar.

1. Entende-se o conceito de 'estrutura cognitiva' como 'ferramenta mental que permite a compreensão de novas realidades, ou seja, como resultado da organização de pensamentos, sentimentos e ações no processo de construção do significado pessoal de uma experiência que permite dar significado a novas experiências". (Balula, 2010) 


\section{Avaliação das aprendizagens - o conceito}

Tendo em conta a crescente utilização da internet e das TICs em contexto educativo, tem-se vindo a repensar o papel/função da avaliação no processo de ensino e de aprendizagem. Ainda assim, o conceito de 'avaliação das aprendizagens' tem sido definido como "o processo pelo qual, de forma mais ou menos sistemática, se recolhem, interpretam e usam informações, de diversos tipos e fontes, para julgar e tomar decisões acerca da aprendizagem dos alunos" (Ferreira, 2003, p. 83). Em boa verdade, este conceito, em si mesmo, remete para uma visão mais tradicional, centrada nos produtos de aprendizagem dos alunos do ponto de vista somativo, com propósitos de certificação e de seleção.

Todavia, se se aplicar este conceito numa perspetiva de avaliação para a aprendizagem', neste caso a avaliação assume o papel de diagnóstica e/ou formativa, centrando-se não apenas nos alunos e para os alunos, mas numa dinâmica aluno/professor/aluno baseada em dinâmicas de feedback (Boud, 2004). Por outras palavras, o resultado desta avaliação é frequentemente utilizado para o professor informar o aluno em relação à sua preparação (estruturas cognitivas prévias necessárias) para alcançar os objetivos pedagógicos - perspectiva diagnóstica - e em relação ao seu sucesso relativo no desenvolvimento dos objetivos pedagógicos definidos - perspetiva formativa. Para além disto, se destes resultados o professor também puder refletir sobre as estratégias de ensino que utilizou e sobre a sua própria atuação como agente de ensino, este será necessariamente um processo mais rico, uma vez que, assim, o professor terá a oportunidade de ajustar a sua atividade futura às necessidades dos alunos, detectadas no próprio processo de avaliação. Esta será, então, uma avaliação mais centrada nos processos do que nos produtos, porque não acontece apenas em fases finais de um processo de ensino/aprendizagem. Salientam-se ainda algumas das características que deverão ser tidas em conta nos processos de avaliação, nomeadamente: ser um processo contínuo, sistemático, subjetivo e prescritivo; estar dependente dos objetivos pedagógicos e do seu contexto específico; e ser pluriforme, ou seja, fazer uso de instrumentos variados. (Valadares \& Graça,1998)

Estudos sobre a integração das TICs em múltiplos contextos educativos têm vindo a demonstrar que os processos de ensino e de aprendizagem frequentemente extrapolam os espaços formais de ensino (presenciais ou on-line). Na verdade, trazem para os contextos formais a possibilidade de desenvolver competências e construir novo conhecimento de forma mais autêntica (Wiggins, 1998; Anderson, 2001), significativa e até sustentável (Boud, 2000); isto porque a comunicação on-line multicanal abre possibilidades de contacto com o mundo real - com especialistas nas mais diversas áreas científicas, com profissionais no ativo, com comunidades de aprendizagem distribuídas que partilham interesses idênticos. Este cenário dá, assim, espaço a que se atribuam novos papéis à avaliação e que 
esta se possa entender como momentos efetivos de aprendizagem. A 'avaliação como aprendizagem' não reflete necessariamente um olhar completamente novo sobre a forma como os professores avaliam os seus alunos; no entanto, pretende relevar a função integrada e integradora do processo de ensino e aprendizagem - em que processos e produtos de aprendizagem se constituem como 'objeto de avaliação' (William, 2011). Esta assenta em dinâmicas de feedback dado e recebido, sendo que os atores poderão não ser apenas o professor e o aluno indivíduo, mas também a comunidade de aprendizagem em que se insere loutros alunos, tutores, especialistas...). (JISC, 2010)

Por fim, neste contexto, podem realçar-se vários indicadores que revelam o nível de qualidade da avaliação das aprendizagens, de entre os quais: i) não se confinar ao momento final de certificação (produtos), mas ser tratada por todos os intervenientes como parte integral do processo de ensino $\neg$ aprendizagem, ii) serem-lhe identificados múltiplos papéis, ii) rejeitar a reprodução acrítica dos conteúdos, centrando-se na capacidade de análise e de síntese de informação, assim como na sua aplicação contextualizada e iii) recorrer a vários métodos e instrumentos. (James et al., 2002)

\section{Avaliação das aprendizagens - o objeto de avaliação}

Tal como defendem Hadji (1994) e Balula (2006; 2010), os objetivos pedagógicos delineados pelo professor podem traduzir-se em vários objetos de avaliação; sendo que estes se podem equacionar em função de dois eixos:

- o eixo do concreto/abstracto - separação entre o que é comportamento esperado e desempenho observável;

- e o eixo funcional/estrutural - separação entre os processos e os produtos do pensamento.

Sobre ambos os eixos, Balula (2010) delimitou também três domínios possíveis de objectos de aprendizagem: o 'domínio dos saberes' e o 'domínio das competências' como abstractos e o 'domínio das competências em situação' como concreto. Já em relação ao segundo eixo, o 'domínio dos saberes' posiciona-se como funcional, o 'domínio das competências' como estrutural e o 'domínio das competências em situação' como simultaneamente estrutural e funcional (Figura 1). Estes domínios do objeto de avaliação, tal como estão representados na Figura. 1 , devem ser vistos como independentes, mas não como estanques, uma vez que não se excluem mutuamente. 


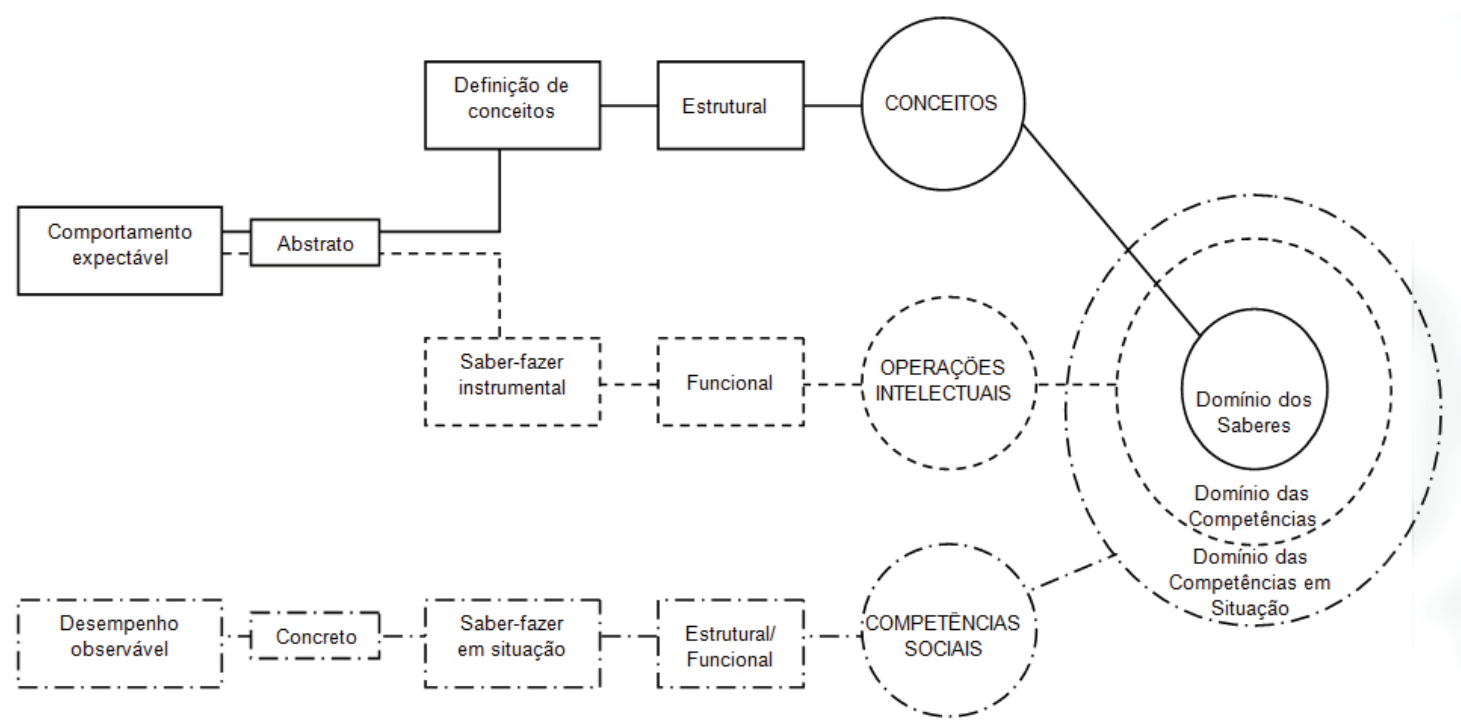

Figura 1 - Representação do objeto da avaliação das aprendizagens: domínio dos saberes, das competências e das competências em situação. (Balula, 2010, p. 41)

Ainda de acordo com o apresentado na Figura 1, os objetivos pedagógicos de cada um destes domínios irão traduzir-se em objetos de avaliação:

- em relação aos conteúdos, no campo da representação dos conceitos;

- em relação às operações intelectuais ou cognitivas, no campo do saber fazer instrumental;

- e em relação às tarefas socialmente significativas, ou competências sociais, no campo do saber fazer em situação.

Na verdade, vários estudos (James et al., 2002; Balula, 2006; 2010) apontam que, em ambiente on-line, é fundamental que as atividades e tarefas propostas aos alunos se constituam de elementos de avaliação com critérios, indicadores e pesos definidos a priori. Nesta ótica, haverá vantagem não só em se entender a avaliação como aprendizagem, mas também que esta inclua, de forma integrada, os vários domínios acima sistematizados - 0 dos saberes, 0 das competências e o das competências em situação. (Figura 1)

Embora se esteja a equacionar o objeto da avaliação das aprendizagens do ponto de vista teórico, do ponto de vista prático não será difícil imaginar que, no âmbito de uma disciplina inicial, o professor possa definir atividades de caráter mais conceptual, a partir das quais este pretende que os alunos (re)estruturem o seu conhecimento teórico em relação a um determinado tema (domínio dos saberes) e que, posteriormente, seja proposta uma tarefa que implique a aplicação numa perspetiva instrumental do conhecimento construído (domínio das competências). Por outro lado, também se pode recorrer a atividades que se 
situem no domínio das competências em situação, por exemplo, com o objetivo de verificar aplicabilidade prática real de conhecimentos teóricos no sentido de reestruturar e enriquecer, a posteriori, estruturas cognitivas prévias (domínio dos saberes) levando ao desenvolvimento de estruturas cognitivas mais complexas.

Pode, então, concluir-se que há vantagens em que a forma como se avalia reflita não só o que se aprende (produtos), mas também como se aprende (processos). Neste sentido, não será demais relembrar que, numa fase anterior à atual profusão das tecnologias nos contextos de ensino, a aprendizagem le, consequentemente, a sua avaliaçãol tendia a acontecer em espiral. Por outras palavras, o aluno aprendia e era avaliado numa perspectiva gradual, por fases - dos conteúdos e competências mais simples para os mais complexos -, e o papel do aluno neste processo era, essencialmente, o de receptor e reprodutor de conhecimento, uma vez que todo o processo se centrava na perspetiva do professor sobre o conhecimento e sobre o que este entendia que o aluno seria capaz de realizar. Neste momento, com sistemas de ensino que pretendem ir ao encontro das necessidades de uma sociedade de informação gerada e alimentada pela comunicação com o outro, o saber de cada um (como indivíduo ou como grupo) tende a ser rentabilizado para o desenvolvimento do conhecimento da comunidade de aprendizagem. Isto leva a que os processos de ensino e de aprendizagem (formais e informais) se concretizem, cada vez mais, em rede e que, como defende Junqueira (2012), se tenham de equacionar novas perspectivas de avaliação do aluno de ensino à distância no paradigma da cibercultura e da web 2.0.

\section{Avaliação das aprendizagens - os instrumentos de avaliação}

Tradicionalmente, quando se fala em avaliação das aprendizagens no âmbito de cursos formais, a tendência é que esta ocorra em ambiente presencial, independentemente de todo (ou grande parte dele) o processo de ensino e de aprendizagem ocorrer em contexto on-line. Isto prende-se, essencialmente, à necessidade de autenticar a identidade do indivíduo que está a ser avaliado, o que tem levado inclusive a que haja diretivas ministeriais em vários países (Portugal, Brasil...) que explicitamente prevejam o contacto presencial em momentos de avaliação.

Hoje em dia, já se encontram estudadas e documentadas experiências educativas em diversos níveis de ensino que não descartam a existência de momentos de avaliação presencial, mas que já apontam soluções complementares de avaliação on-line (Balula, 2010). De entre os instrumentos mais comumente utilizados on-line, surgem: i) os testes (com questões de resposta fechada e/ou aberta), ii) os trabalhos escritos (individuais ou em grupo, de cariz colaborativo ou não), iii) a participação on-line (quantitativa e/ou qualitativa) e iv) a auto e heteroavaliação (quantitativa ou qualitativa). Nas secções que se seguem, apresenta-se uma reflexão sobre estes instrumentos em função da sua incidência sobre os três domínios de aprendizagem acima apresentados. 


\section{Teste}

Os testes são instrumentos de avaliação individual e, regra geral, confinados a um espaço de tempo curto. Estes podem incluir questões de resposta fechada e são muito utilizados em ambiente on-line e presencial, uma vez que permitem uma correção mais célere lou até automátical - alguns autores chegam a caracterizálos como mais "objetivos". Com efeito, considera-se que o adjetivo 'objetivo' se refere ao tipo de resposta esperada, uma vez que apenas admitirá uma quantidade limitada de respostas (regra geral uma), e não à construção da prova em si, sendo que esta está naturalmente subjetiva na medida em que a formulação das perguntas e eventuais respostas, ou até mesmo a seleção das temáticas a abordar, estão dependentes da perspetiva do professor e, portanto, da sua subjetividade.

Desta tipologia de instrumento farão parte as questões do tipo resposta múltipla, verdadeiro ou falso, preenchimento de espaços e associação/correspondência - que, geralmente, não fomentam a apresentação do raciocínio e da aplicação de conteúdos em contexto, mas sim a demonstração de memorização/retenção de conceitos e/ou de conteúdos factuais. É uma tipologia que "ensina" ao aluno que existe apenas uma resposta certa para uma questão ou problema, o que na prática nem sempre corresponde à realidade. Isto leva a que autores como Gil (2002, p. 6) afirmem que "sendo de grande conveniência prática leconomia de tempo de classificação, (...) [estes] não podem ser utilizados em exclusivo", uma vez que os resultados aferidos tendem a situar-se no domínio dos saberes, ou seja, no campo da representação conceptual. Na melhor das hipóteses, este tipo de instrumento poderá incidir sobre o domínio das competências, se for solicitada ao aluno a operacionalização de conceitos do ponto de vista teórico, numa perspetiva do saber-fazer instrumental.

Existe também a possibilidade das questões de resposta aberta, as quais podem implicar mais do que a definição conceptual; todavia, tendo em conta que as respostas tendem a ser dadas num espaço e tempo muito delimitado, não permitindo o recurso a outras fontes de informação ou aplicação em contextos reais, o objecto de avaliação poderá situar-se também no domínio das competências, da operacionalização intelectual do conhecimento.

\section{Trabalho escrito}

0 trabalho escrito, regra geral, é feito em contexto fora de aula, recorrendo a diversas fontes de informação, tendo como objetivo a sistematização e/ou discussão de informação, e podendo refletir (ou não) a aplicação prática de conceitos teóricos. Nesta medida, o objeto de avaliação poderá situar-se num ou 
vários dos domínios acima apresentados, o que está intrinsecamente dependente do enunciado/problema definido pelo professor. A título de exemplo, se se tratar de um trabalho de revisão da literatura, este talvez se situe mais no domínio dos saberes ou das competências (dependendo do grau de complexidade de interligação do conhecimento teórico); por sua vez, se assumir o formato de relatório, em que se preveja uma aplicação em contexto real dos pressupostos teóricos e a sua posterior discussão crítica, então, talvez se situe no domínio das competências em situação. Em muitos casos, tendem até a englobar os três domínios de forma dinâmica - levando à evolução do próprio conhecimento individual e coletivo.

Regra geral, consideram-se duas tipologias de trabalho escrito - o trabalho individual e o de grupo. Esta dicotomia não deve, no entanto, ser encarada como processual, mas em relação aos produtos da própria aprendizagem. Isto porque, por um lado, o trabalho individual poderá ser redigido por um só indivíduo, mas contar com a partilha e discussão dos saberes com outros indivíduos que não estão a ser avaliados. Por outro lado, no trabalho de grupo, o produto final pode surgir numa lógica de cooperação, em que cada elemento produz uma parte de forma autônoma e o produto final é a soma das diversas partes, ou pode resultar de um processo colaborativo de partilha e discussão efetiva entre os vários elementos le até elementos externos ao grupo e à própria comunidade de aprendizagem). Por outras palavras, qualquer trabalho (individual ou de grupol poderá ser pensado para implicar dinâmicas de colaboração, ou não. Desta forma, quando se pretende que o conhecimento seja construído de forma partilhada e distribuída com uma comunidade, para além de partilhar dos mesmos objectivos de aprendizagem, esta deve caracterizar-se, de entre outras coisas, i) pelo compromisso e empenho de todos os elementos na geração e partilha de novo conhecimento, ou seja, antes de iniciar um processo intrapsicológico de reestruturação do conhecimento em relação às estruturas previamente existentes, a interiorização envolve uma atividade externa interpsicológica (com o outro); e ii) pelo alto nível de diálogo, interação e colaboração através da partilha e discussão constante entre os elementos de uma comunidade. A verificação destes aspectos, levará a que a comunidade se possa considerar uma comunidade de aprendizagem distribuída (CAD).

0 desenvolvimento das TICs tem levado a que se perspective o conceito de CAD tendo em conta outros vectores, nomeadamente os relacionados com as formas de comunicação. Uma das vantagens da utilização das TICs é o facto de permitir a existência de uma aprendizagem contextualizada, ou seja, de permitir que se criem realidades virtuais que façam o enquadramento das matérias abordadas, para que o indivíduo assimile melhor o conhecimento que constrói e tenha mais facilidade em transpor esse mesmo conhecimento para novas situações - domínio das competências em situação. 


\section{Participação on-line}

A possibilidade de incluir a participação on-line como elemento de avaliação, assim como a sua operacionalização, são questões que têm sido bastante discutidas, em especial no contexto de cursos com componentes on-line lem bLearning ou eLearningl. Numa fase inicial, a tendência era que esta se baseasse em evidências de cariz quantitativo, ou seja, que assentasse na quantidade de vezes que os alunos acediam a conteúdos ou utilizassem ferramentas de comunicação dentro de sistemas fechados e restritos a uma determinada comunidade de aprendizagem, nomeadamente, plataformas de ensino on-line (como o Blackboard ou o Moodle). Isto porque as próprias plataformas incluíam funcionalidades que permitiam a geração automática de relatórios de acessos por aluno. Rapidamente se concluiu que a quantidade de acessos poderia ser motivada por factores contextuais e que poderiam não refletir o verdadeiro envolvimento do aluno. Consequentemente, começou-se a estudar possibilidades de o objeto de avaliação ser a qualidade da participação on-line, no tempo disponível para uma determinada tarefa ou disciplina. Tal como refere Gil (2002):

(...) como os objectivos de aprendizagem são definidos qualitativamente, uma avaliação a eles referida é, por isso, subjetiva, isto é, imprecisa e sujeita a factores estranhos. Por outro lado, as técnicas de avaliação mais quantitativas só aparentemente são menos subjetivas, pois supõem minijuízos de valor, por exemplo aquando da concepção e da cotação das questões para um exame.(...) Uma abordagem numérica em que o todo seja visto com a soma das partes (hermenêutica) trata como igual o que é diferente, por exemplo, ao atribuir a mesma nota a perfis de aprendizagem que podem ser muito diferentes. (Gil, 2002, p. 2-3)

De qualquer das formas, considera-se que o posicionamento mais vantajoso será o equilíbrio entre ambas para que delas se possa retirar o que melhor nos oferecem, ou seja, deverá procurar conjugar-se o sistema quantitativo (numérico) com o que se infere do ponto de vista qualitativo (em relação aos processos), para que a avaliação das aprendizagens seja mais eficaz.

A avaliação da participação on-line deverá, neste sentido, consistir na avaliação do contributo do aluno para a construção do conhecimento da CAD em causa. Contudo, a tarefa não se revela tão simples quanto aparenta, uma vez que a maioria das plataformas em que assentam estes cursos apenas possibilitam que se faça uma contabilização das participações ou das visitas a determinadas áreas da própria plataforma e não contemplam mecanismos, por exemplo, de avaliação qualitativa das participações nos fóruns de discussão. (Balula, 2006)

$\mathrm{Na}$ verdade, um dos grandes problemas que esta avaliação levanta é a carga de trabalho para o professor, quando se pretende tratar um conjunto elevado de 
posts colocados pelos alunos (Santos, 2005). Neste sentido, alguns autores (como Phillips, 2000; Santos, 2005; Balula, 2006) defendem que se poderá aplicar uma escala que permita que o professor atribua uma nota qualitativa às intervenções dos alunos, no sentido de simplificar a tarefa. Como afirma Santos (2005), ainda não foi encontrado nenhum algoritmo matemático que permita a tradução desta categorização dos posts em fóruns (por exemplo) numa nota quantitativa; todavia, a escala que se apresenta de seguida (Tabela 1) permite diminuir a subjetividade da avaliação deste elemento e também o volume de trabalho a ela associada.

Tabela 1 - Escala de avaliação da participação on-line

\begin{tabular}{c|l}
\hline Categoria & \multicolumn{1}{|c}{ Descrição } \\
\hline E & Irrelevante, inútil \\
\hline D & Demonstra acompanhamento das discussões \\
\hline C & $\begin{array}{l}\text { Tentativa de envolvimento na discussão, demonstra pouca } \\
\text { compreensão dos assuntos, não faz progredir o debate }\end{array}$ \\
\hline B & $\begin{array}{l}\text { Bom contributo, demonstra compreensão, faz progredir o } \\
\text { debate }\end{array}$ \\
\hline A & $\begin{array}{l}\text { Excelente contributo, demonstra compreensão profunda, leva } \\
\text { o debate para novas áreas }\end{array}$ \\
\hline
\end{tabular}

Fonte: Santos, 2005.

Desta maneira, e de acordo com o apresentado na tabela 1, deve ser atribuída uma notação maia alta às participações dos alunos que conduzem a uma compreensão mais sustentada e a uma discussão aprofundada de uma determinada temática. Contudo, também deve ser valorizado o contributo dos elementos ou grupos para o crescimento do grupo enquanto comunidade, numa perspetiva de entreajuda. Se se tiverem em conta estes pressupostos, a avaliação da participação on-line não só reflete o processo de aprendizagem, como também permite individualizar o desempenho do aluno em relação à sua própria construção do conhecimento e ao seu papel na CAD. (Balula, 2005)

No que se refere a ferramentas de comunicação on-line, a escolha mais frequente recai sobre fóruns de discussão fechados (dentro das plataformas de eLearningl, mas estas participações tendem a ser cada vez mais complementadas por estratégias que preveem a utilização de outras ferramentas da web social (Facebook, Flickr, Delicious, YouTube...). Isto tem a clara vantagem de valorizar o contacto dos alunos com informação de diferentes fontes e em variados formatos (texto, áudio, vídeo...), o que acaba por refletir o seu próprio processo de aprendizagem, que tende a estruturar-se em rede. Por outras palavras, confere-lhes o poder e a responsabilidade de seleção e validação da informação, 
contribuindo para o esclarecimento e desenvolvimento da sua aprendizagem enquanto indivíduo e elemento de uma comunidade.

Em suma, se se assumirem estes pressupostos, e à semelhança do que acontece com o trabalho escrito, é natural que este elemento de avaliação da aprendizagens opere nos domínios dos saberes das competências e/ou das competências em situação, dependendo das tarefas definidas pelo professor.

\section{Auto e Heteroavaliação}

Na avaliação das aprendizagens, o principal ator tende a ser o professor. Todavia, incluir a auto e heteroavaliação como elemento de avaliação das aprendizagens é permitir que os alunos também tenham uma participação ativa no processo. Isto irá permitir reduzir o pendor subjetivo da avaliação e também leva a que esta não assente apenas nas percepções dos professores em relação ao desempenho dos alunos.

Este elemento pode assumir-se também como qualitativo ou quantitativo; mas acredita-se que há vantagem em que os alunos a realizem de forma qualitativa, nomeadamente porque, se assim for, os alunos passam a integrar de forma ativa o processo de avaliação do seu desempenho e do dos colegas, e remete-se para o professor a decisão última da tradução dessa avaliação qualitativa em quantitativa - permitindo contornar situações em que alguns alunos atribuem notas de forma acrítica ou apenas por simpatizarem (ou não) com um colega.

Quanto à forma, é comum que seja solicitado aos alunos que se autoavaliem e que, quando trabalham em grupo, avaliem os restantes elementos do seu grupo. Contudo, existem outras formas de heteroavaliação a considerar, nomeadamente a intergrupal (de um grupo em relação ao desempenho de outro grupo) ou dos alunos, enquanto indivíduos, em relação ao desempenho dos grupos a que não pertenceram. Na verdade, estas últimas estratégias têm-se revelado interessantes, na medida em que implicam que os alunos partilhem o seu trabalho ao longo do percurso de aprendizagem e possam comentar também o de outros grupos. (Pombo et al., 2009)

Estes elementos de avaliação das aprendizagens podem, então, revelar-se de bastante utilidade para o próprio professor, uma vez que implicam que os alunos façam uma apreciação crítica consciente do trabalho que desenvolveram e dos seus próprios produtos, assim como dos da CAD - no domínio dos saberes, das competências e/ou das competências em situação, sempre tendo em conta os objetivos pedagógicos definidos a priori pelo professor.

Em suma, em especial em ambiente on-line, é importante favorecer a responsabilização do aluno sobre a sua própria aprendizagem, o que pode ser feito através da auto- e da heteroavaliação. Se estas forem aplicadas no decorrer 
do processo de ensino e de aprendizagem e não apenas no final, esta será também uma forma de auto e heterorregulação do processo educativo, estimulando os alunos (e o professor) a identificar dificuldades e a encontrar soluções para ultrapassar esses obstáculos. (Hadji, 1994)

\section{Possibilidades de operacionalização}

Nesta secção, não se pretende apresentar a(s) fórmula(s) que garante(m) o sucesso da utilização dos instrumentos acima apresentados, mas sim avançar com algumas estratégias consideradas "boas práticas" para cursos totalmente lou com uma forte componente) on-line, nos quais se pretende que a aprendizagem dos alunos se desenvolva numa perspetiva de colaboração.

Tendo em conta a revisão da literatura efectuada, quando se pretende desenvolver competências de colaboração, o instrumento de avaliação (e de aprendizagem) que tende a ser menos utilizado é o teste. Por oposição, o instrumento mais frequente tende a ser o trabalho de grupo, ainda que em articulação com outros instrumentos (Balula \& Moreira, 2010) - por razões várias, entre as quais se salienta o facto de o aluno não se sentir tão isolado (por estar geograficamente distante da comunidade que integral e de este permitir o desenvolvimento de novo conhecimento de forma mais partilhada e rica.

Existem várias tipologias de enunciado para o trabalho de grupo, sendo que a mais comum é a definição de uma tarefa igual para todos os grupos - esta é muito utilizada, mas levanta várias questões, nomeadamente o facto de: i) não fomentar a partilha de informação e a sua discussão entre os vários grupos, uma vez que se pretende um produto final idêntico para todos os grupos; ii) não ser enriquecedora para o grupo/turma, na medida em que não suscita a curiosidade intergrupal, nem a partilha de resultados; entre outras.

Existem, no entanto, outras estratégias para operacionalizar os instrumentos de avaliação em ambiente on-line que podem ser mais interessantes e que podem colmatar estes e outros constrangimentos. Uma delas passa pela definição de uma tarefa igual para todos os grupos, mas dando liberdade a cada grupo para escolher o seu objeto de estudo. Pombo et al. (2009), por exemplo, referem que foi proposto a todos os alunos que fizessem uma avaliação de software educativo, tendo por base os mesmos pressupostos teóricos, mas que cada grupo selecionasse um software para avaliar, ou seja, o objeto de estudo. Para além disto, as autoras (Pombo et al., 2009) relatam que houve o cuidado de garantir que não haveria dois grupos a operar sobre o mesmo objeto. Este fator assume importância, não só porque não condiciona a partilha de informação entre os grupos, mas também porque fomenta o interesse dos diversos grupos nos trabalhos dos colegas. Releva-se que para isto também contribuiu uma estratégia de heteroavaliação intermédia não 
intragrupal - ou seja, todos os alunos avaliaram o produto final do trabalho dos grupos a que não pertenciam (que teriam necessariamente de ler e comentar), e era dada a oportunidade aos alunos de melhorarem o seu trabalho tendo em conta os comentários dos colegas (numa perspetiva de avaliação como aprendizagem).

Outra das estratégias de trabalho de grupo encontradas passa pela definição de um problema real, complexo e multidimensional para a turma, cabendo a cada grupo a responsabilidade do desenvolvimento de uma tarefa parcelar, para contribuir para a sua resolução. A título de exemplo, refere-se o caso estudado por Balula \& Moreira (2010), no qual o problema inicial colocado aos alunos passava pelo desenvolvimento de um projeto piloto para criar e equipar um espaço no qual alunos regulares poderiam aprender a utilizar as TICs depois das aulas e no qual também se poderiam integrar alunos com necessidades especiais (limitações físicas...). Mediante este problema, a turma assumiu-se como um conjunto de peritos que iria trabalhar de forma colaborativa para apresentar soluções tecnológicas e pedagógicas (articuladas) para o problema inicial. Como refere Balula et al. (2004:10), este tipo de enunciado leva a uma "necessidade imperativa de comunicação e partilha das soluções que cada grupo foi desenvolvendo, uma vez que a validade do trabalho se encontraria na conjunção dos trabalhos de cada grupo." A tarefa implicava processos de interação/negociação entre os diversos grupos com vista a articular a melhor solução para o problema inicial, o que, por isso mesmo, acaba por remeter para uma aprendizagem autêntica muito próxima de contextos profissionais reais - domínio das competências em situação lver Fig.11. Talvez devido à complexidade deste tipo de trabalho em grupo e também porque extrapola a constituição dos próprios grupos em processos de negociação e na articulação com outros grupos, este foi articulado com um momento de auto- e heteroavaliação que se consubstanciou numa pergunta do teste escrito (individual) final, em que era solicitada aos alunos uma descrição sucinta do seu trabalho (no que respeita aos processos de criação e de negociação com os outros grupos de trabalho), com o objetivo claro de aferir a participação/entrosamento de cada elemento no trabalho do próprio grupo.

Um último exemplo de estruturação de trabalho de grupo, no qual a heteroavaliação assume bastante relevância: foi proposto aos alunos que estruturassem e implementassem um curso de curta duração (3 dias), tendo com base a plataforma de eLearning (Balula, 2006). Durante estes dias, os alunos de cada grupo foram simultaneamente professores/tutores do curso que criaram e alunos de um curso implementado por outro grupo de trabalho. No final, todos os elementos dos grupos avaliaram os seus "alunos", fizeram a sua autoavaliação e foram também eles avaliados pelos seus "alunos" (colegas, portanto) (Balula, 2006). Esta dinâmica de auto- e heteroavaliação permitiu que o docente não tivesse de acompanhar absolutamente toda a interação gerada, mas que tivesse dados para avaliar o desempenho dos diversos elementos de cada grupo. Para além disto, trata-se de uma estratégia que não estimula, por exemplo, situações de plágio e 
que leva a que os alunos desenvolvam competências de forma participada e em contextos autênticos - domínio das competências em situação (ver Figura1).

Em suma, nos casos acima apresentados, a participação on-line assume bastante relevância, não só porque dela (de uma forma ou de outra) dependeu o sucesso dos trabalhos de grupo, mas também porque permitiu centrar a avaliação no aluno e incluir os próprios alunos no processo avaliativo. Nos últimos casos, esta participação foi considerada ainda como parâmetro de avaliação individual - 0 professor definiu que a participação individual de cada aluno, num fórum destinado à partilha e discussão de questões teóricas, iria ser avaliada de acordo com a escala de avaliação da participação on-line acima apresentada (ver Tabela 1). A participação on-line assume-se, portanto, como multidimensional e fundamental para que o enfoque da avaliação das aprendizagens seja nos processos e não apenas nos produtos, podendo permitir ainda que esta avaliação seja individualizada, mas também participada.

\section{Considerações finais}

A oferta de curso/disciplina em ambiente on-line é, definitivamente, uma maisvalia para garantir o acesso à educação a alunos que se encontram distribuídos por uma grande extensão geográfica, ou que não têm condições econômicas ou facilidades do ponto de vista profissional que permitam a sua deslocação regular. Em contraste, advêm deste mesmo contexto on-line constrangimentos em relação à avaliação das aprendizagens e consequente certificação, nomeadamente no que se refere à identificação dos indivíduos (autenticidade). Ainda assim, foram e vão sendo apontados alguns caminhos para ultrapassar estes obstáculos, e um deles (talvez o mais relevante) é centrar mais a avaliação das aprendizagens on-line nos processos de aprendizagem dos alunos - individuais e em grupo.

Neste sentido, assume cada vez mais relevância que a avaliação das aprendizagens on-line assente em mais do que um instrumento, em mais do que um momento e em mais do que um indivíduo. Por outras palavras, parece haver vantagem em que se diversifique a avaliação das aprendizagens, distribuindo os elementos de avaliação no tempo e procurando envolver a toda a comunidade (alunos, professor, tutor) na avaliação. Ressalva-se que não se deverá excluir a possibilidade de inclusão de elementos externos, se estes forem chamados a contribuir, na sua especialidade, para o desenvolvimento do conhecimento da CAD. Esta abordagem vem valorizar a aprendizagem e a sua avaliação em rede, numa perspetiva tentacular quanto aos intervenientes, aos espaços e até aos instrumentos, o que vem ao encontro da forma plural como partilhamos informação e nos relacionamos com o outro, tendo por base a interação baseada nas TICs.

Em termos de desempenho individual dos aluno, conclui-se também que a sua 
avaliação não fica comprometida se a avaliação das aprendizagens não se basear apenas no produto final de um trabalho realizado em grupo e se forem adotadas estratégias que não dependam apenas do professor. Deverão, por conseguinte, equacionarem-se sempre as vantagens de incluir a participação on-line e a auto e heteroavaliação do trabalho desenvolvido on-line, que pode passar pela utilização de várias ferramentas de comunicação síncrona e assíncrona, como são o chat, a videoconferência, o fórum de discussão, a wiki, o blog, o Facebook...

Por fim, em relação à questão da autenticidade dos resultados alcançados pelos alunos, devido à falta de contacto presencial ao longo do processo de avaliação das aprendizagens on-line, releva-se a importância da criação de contextos de aprendizagem (e de avaliação das aprendizagens) inovadores e autênticos, assim como a proposta de tarefas que os alunos possam transferir para contextos reais e para as quais não haja uma solução única, uma vez que tal poderá diminuir drasticamente o risco de plágio e servir de elemento motivador para o aluno.

Termina-se este trabalho reforçando que não existem fórmulas únicas para garantir o sucesso da avaliação das aprendizagens em ambiente on-line, mas acreditando que é determinante que o professor defina os objetivos pedagógicos em articulação com as tarefas de avaliação (e, concomitantemente, de aprendizagem) e tenha sempre em mente o domínio da aprendizagem que pretende explorar.

\section{Referências}

ANDERSON, Janice. Final Report: Flexible Learning Leaders. Research Investigation on Online Assessment as an Integral Part of Flexible Online Delivery. 2001. Disponível em: http://flexiblelearning.net.au/leaders/past_fellows/2001/janice_anderson.htm. Acesso em: 5 out. 2012.

BALULA, Ana; MOREIRA, António. Hows and Whys in Online Assessment. International Journal of Information and Operations Management Education, 3(4), pp. 382-391. Inderscience Publishers. 2010.

BALULA, Ana; PAIS, Fátima; MOREIRA, António. O Papel das estratégias num curso em bLearning: 0 Caso do Mestrado/CFE em Multimédia em Educação - 2003/2004. eLES'04 - eLearning no Ensino Superior. Aveiro: Universidade de Aveiro. 27-30 out. 2004.

BALULA, Ana. A Avaliação das Aprendizagens em contexto de eLearning, Novla Formação - "eLearning e Avaliação - Métodos e Indicadores". Lisboa: Inofor, 6, pp.710, dez. 2005.

BALULA, Ana. E-assessment no Ensino Superior: Constrangimentos e Potencialidades. Dissertação de Mestrado [não publicada]. Disponível em: http://ria.ua.pt/ handle/10773/1376. Universidade de Aveiro. 2006. Acesso em: 23 set. 2012.

BALULA, Ana. Proposta de Modelo de Avaliação das Actividades de Ensino Online - Um 
Estudo do Ensino Superior Português. Tese de Doutoramento [não publicada]. Disponível em: http://ria.ua.pt/handle/10773/1123. Universidade de Aveiro. 2010. Acesso em: 25 set. 2012.

BOUD, David (2004). Creating assessment for learning through life. In GIL, Victor; ALARCÃO, Isabel; HOOGHOFF, Hans. Chalenges in Teaching \& Learning in Higher Education, Aveiro: Universidade de Aveiro. 2004.

BOUD, David. Sustainable Assessment: rethinking assessment for the learning society. Studies in Continuing Education, 22, 2, 151-167. 2000.

FERREIRA, Cristina. A Avaliação das aprendizagens no Trabalho Laboratorial em Biologia: uma proposta para o ensino secundário. Dissertação de Mestrado [não publicada]. Universidade de Aveiro. 2003.

GIL, Victor. Avaliação das Aprendizagens no Ensino Superior. Texto apresentado a 2 de Outubro de 2002, na Universidade de Aveiro, no formato de Comunicação convidada, na Jornada "Avaliação Contínua no Ensino Superior", promovida pelo Instituto de Formação Inicial Universitária e pelo Conselho Pedagógico da UA. [não publicado]. HADJI, Charles. A Avaliação, Regras do Jogo. Porto: Porto Editora. 1994.

JAMES, Richard; McINNIS, Craig; DEVLIN, Marcia. Assessing Learning in Australian Universities. Australia: Australian Universities Teaching Committee. 2002. Disponível em: http://www.cshe.unimelb.edu.au/assessinglearning/docs/ AssessingLearning. pdf. Acesso em: 23 set. 2012.

JISC. Effective Assessment in a Digital Age: A guide to technology-enhanced assessment and feedback. HEFCE, 2010.

JUNQUEIRA, Eduardo. Linhas Críticas. Brasília, DF, n.36, p.417-431, maio/ago. 2012.

PHILLIPS, Rob. Facilitating online discussion for interactive multimédia project management. The OTiS International e-Workshop on Developing Online Tutoring Skills. Aberdeen, Scotland. 8-12 maio 2000. Disponível em: http://researchrepository. murdoch.edu.au/12202/ . Acesso em: 23 out. 2012.

POMBO, Lúcia, BALULA, Ana, LOUREIRO, Maria João \& MOREIRA, António. Diversity of strategies to promote effective b-Learning: a case study in Higher Education. In BERNATH, Ulrich, SZÜCS, András; TAIT, Alan; VIDAL, Martine. Distance and Elearning in Transition - Learning Innovation, Technology and Social Challenges. London: ISTE \& John Wiley \& Sons, Inc., pp. 627-644. 2009.

SANTOS, Carlos. Avaliação da participação on-line em ambientes de e-Learning - a metodologia desenvolvida para aplicação em duas disciplinas do Mestrado/CFE Multimédia em Educação da Universidade de Aveiro, Novla Formação - "eLearning e Avaliação - Métodos e Indicadores". Lisboa: Inofor, 6, pp.33-36, dez. 2005.

VALADARES, Jorge; GRAÇA, Margarida. Avaliando para melhorar a aprendizagem. Lisboa: Plátano Edições Técnicas, 1998.

WIGGINS, Grant. Educative assessment. San Francisco: Jossey Bass, 1998.

WILLIAM, Dylan. What is assessment for learning?. Studies in Educational Evaluation, 37, pp. 3-14. 2011. 
Recebido em dezembro de 2012

Aprovado em julho de 2013

Ana Jorge Balula Pereira Dias é docente da Universidade de Aveiro. Doutorou-se em Multimédia em Educação na mesma Universidade, na área de Avaliação do Ensino. E-mail: balulađua.pt 